\title{
Effects of L-carnitine, Selenium-enriched Yeast, Jujube Fruit and Hwangto (Red Clay) Supplementation on Performance and Carcass Measurements of Finishing Pigs
}

\author{
Yung-Keun Han* and P. A. Thacker ${ }^{1}$ \\ Food Science \& Biotechnology, Sungkyunkwan University, Suwon 440-746, Korea
}

\begin{abstract}
Fifty castrated crossbred (Landrace $\times$ Yorkshire) pigs, weighing an average of $60.6 \pm 3.1 \mathrm{~kg}$ were allotted to one of five treatments in a randomized block design to examine the effects of dietary inclusion of $0.1 \%$ L-carnitine ( 50 ppm carnitine), $0.1 \%$ selenium-enriched yeast (0.3 ppm selenium), $0.1 \%$ Jujube fruit or $0.1 \%$ Hwangto (Red clay) on pig performance and carcass quality. All diets were based on corn, wheat, soybean meal and wheat bran and were formulated to supply 13.8 MJ DE/kg. Dietary supplementation did not influence daily gain $(p=0.57)$, feed intake $(p=0.52)$, or feed conversion $(p=0.32)$. Digestibility of dry matter $(p=0.60)$, organic matter $(p=0.74)$, crude protein $(p=0.76)$, crude fibre $(p=0.70)$ and energy $(p=0.75)$ were also unaffected by inclusion of any of the additives. Tissue samples taken from the longissimus muscle showed that the levels of carnitine $(p=0.0001)$ and selenium $(p=$ 0.0001) were significantly higher with dietary inclusion of carnitine or selenium-enriched yeast. Dietary treatment did not affect dressing percentage $(p=0.33)$, carcass lean yield $(p=0.99)$ or first, $10^{\text {th }}$ and last rib midline backfat depth $(p=0.45,0.82$ and 0.47 , respectively). Dietary treatment also did not affect the percentages of tenderloin $(p=0.37)$, bacon $(p=0.36)$, fat and bone $(p=0.56)$, picnic shoulder $(p=0.25)$, skirt $(p=0.80)$, fresh ham $(p=0.31)$ or ribs $(p=0.79)$. However, pigs fed the diet containing Jujube fruit had a higher percentage of Boston butt than pigs fed the carnitine or selenium supplemented diets $(p=0.01)$. Pigs fed added Hwangto had a higher $(p$ $=0.04$ ) percentage of loin compared with pigs fed supplementary selenium or Jujube fruit. Loin muscle from pigs fed carnitine had a significantly lower Hunter colour value for $\mathrm{L}$ (whiteness, $\mathrm{p}=0.004$ ) and a higher value for $\mathrm{a}$ ( (redness; $\mathrm{p}=0.069$ ). The overall results indicate that supplementation with L-carnitine and selenium-enriched yeast can produce pork containing higher levels of carnitine and selenium, which could provide health benefits for consumers of pork without detrimental effects on pig performance. (Asian-Aust. $\boldsymbol{J}$. Anim. Sci. 2006. Vol 19, No. 2 : 217-223)
\end{abstract}

Key Words : Carnitine, Selenium, Jujube Fruit, Red Clay, Pigs, Performance, Carcass Traits

\section{INTRODUCTION}

Expanding knowledge of the role of physiologically active components from animal sources has notably changed the role of diet in human health (American Dietetic Association, 2004). Functional foods are usually understood to be any potentially healthful food or food ingredient that may provide a health benefit beyond the traditional nutrients it contains (Wildman, 2001). Functional foods that have been associated with health-related effects include animal products such as eggs with n-3 fatty acids (Farrell, 1998; Lewis et al., 2000), dairy products, and meat from ruminant animals containing conjugated linoleic acid (Belury, 2002).

Carnitine is a vitamin-like compound, which is necessary for the transport of long-chain fatty acids across the inner mitochondrial membrane, thereby facilitating $\beta$ oxidation (Fritz and Yue, 1963). Owen et al. (2001a) reported that feeding L-carnitine during the growingfinishing phase had no effect on pig performance, but may

\footnotetext{
* Corresponding Author: Yung-Keun Han. Tel: +82-31-290-7806, Fax: +82-31-290-7816, E-mail: swisshan@paran.com

${ }^{1}$ Department of Animal Science, University of Saskatchewan, 51 Campus Drive, Saskatoon, Saskatchewan, Canada.

Received April 11, 2005; Accepted August 25, 2005
}

be a means to improve carcass characteristics and tissue carnitine concentration. They reported that $50 \mathrm{ppm}$ added carnitine was sufficient to obtain optimal carcass characteristics and metabolic differences.

Selenium has recognized antioxidant properties. Ku et al. (1972) reported a high correlation between the selenium content of pork loins and the natural selenium content of diets fed to pigs. An organic selenium yeast source resulted in a higher deposition of selenium in muscle than when the inorganic form of the element was provided (Mahan and Parrett, 1996). However, Mahan et al. (1999) reported no benefits in pig performance or carcass traits as a result of altering either the selenium source or the dietary selenium level in pig diets.

Jujube fruit (Zizyphus jujuba) is traditionally used for weakness, fatigue, debility, restlessness, and hysteria as well as to assist in the actions of other herbs (Ou, 1989). Jujube seeds are used for medicinal purpose and increase weight gain, muscular strength, and stamina (Yang, 1998). In Chinese medicine, Jujube is prescribed as a $q i$ tonic to strengthen liver function. Mildly sedative and antiallergenic, it is given to reduce irritability and restlessness (Chevallier, 1998). Scientific studies with animals have shown the Zizyphus jujuba seed to have anti-anxiety effects, causing a reduction in the speed of conditioned reflexes and 
Table 1. Composition and chemical analysis (\% as fed) of the experimental diets

\begin{tabular}{|c|c|c|c|c|c|}
\hline & Control & Carnitine & Selenium & Jujube fruit & Hwangto \\
\hline \multicolumn{6}{|l|}{ Ingredient composition } \\
\hline Corn & 18.00 & 18.00 & 18.00 & 18.00 & 18.00 \\
\hline Wheat & 60.00 & 60.00 & 60.00 & 60.00 & 60.00 \\
\hline Soybean meal (44\% CP) & 16.90 & 16.90 & 16.90 & 16.90 & 16.90 \\
\hline Wheat bran & 1.15 & 1.05 & 1.05 & 1.05 & 1.05 \\
\hline Water & 1.00 & 1.00 & 1.00 & 1.00 & 1.00 \\
\hline Celite-545 & 1.00 & 1.00 & 1.00 & 1.00 & 1.00 \\
\hline Salt & 0.35 & 0.35 & 0.35 & 0.35 & 0.35 \\
\hline Limestone & 0.40 & 0.40 & 0.40 & 0.40 & 0.40 \\
\hline Tri-calcium phosphate & 0.70 & 0.70 & 0.70 & 0.70 & 0.70 \\
\hline Vitamin-trace mineral premix ${ }^{a}$ & 0.50 & 0.50 & 0.50 & 0.50 & 0.50 \\
\hline L-carnitine & 0.00 & 0.10 & 0.00 & 0.00 & 0.00 \\
\hline Selenium-enriched yeast & 0.00 & 0.00 & 0.10 & 0.00 & 0.00 \\
\hline Jujube fruit & 0.00 & 0.00 & 0.00 & 0.10 & 0.00 \\
\hline Hwangto & 0.00 & 0.00 & 0.00 & 0.00 & 0.10 \\
\hline \multicolumn{6}{|l|}{ Chemical analysis } \\
\hline Moisture & 13.37 & 13.37 & 13.37 & 13.37 & 13.37 \\
\hline Crude protein & 16.06 & 16.02 & 16.08 & 16.05 & 16.03 \\
\hline Ether extract & 1.97 & 1.97 & 1.97 & 1.97 & 1.97 \\
\hline Acid detergent fibre & 6.29 & 6.14 & 6.20 & 6.33 & 6.13 \\
\hline Ash & 5.19 & 5.20 & 5.18 & 5.16 & 5.21 \\
\hline Calcium & 0.56 & 0.57 & 0.56 & 0.56 & 0.56 \\
\hline Phosphorus & 0.49 & 0.49 & 0.49 & 0.49 & 0.49 \\
\hline
\end{tabular}

${ }^{\mathrm{a}}$ The vitamin and trace mineral premix provided the following per kilogram of diet: $60 \mathrm{mg}$ Fe; $10 \mathrm{mg} \mathrm{Cu} ; 25 \mathrm{mg} \mathrm{Mn} ; 60 \mathrm{mg} \mathrm{Zn}$; $0.2 \mathrm{mg}$ I; $0.25 \mu \mathrm{g}$ Se; 8,000 IU Vitamin A; 1,500 IU Vitamin $\mathrm{D}_{3}$; 40 mg Vitamin E, 1 mg Vitamin $\mathrm{K}_{3}$; 1 mg Thiamine; 2.5 mg Riboflavin; 2 mg Pyridoxine; 0.01 mg Vitamin $\mathrm{B}_{12} ; 7 \mathrm{mg}$ Pantothenic acid; $15 \mathrm{mg}$ Niacin; $0.05 \mathrm{mg}$ Biotin; $0.5 \mathrm{mg}$ Folic acid and $165 \mathrm{mg}$ Choline.

a reduction in hyperactivity (Park et al., 2000; Han et al., 2001). Because of its stress-reducing effects, the Jujuba can be used as an anti-stress agent.

Hwangto (Red clay) contains $\mathrm{SiO}_{2}$ (50 to $65 \%$ ), $\mathrm{Al}_{2} \mathrm{O}_{3}$ (16 to $24 \%$ ), $\mathrm{Fe}_{2} \mathrm{O}_{3}$ (4 to $9 \%$ ), $\mathrm{MgO}(0.6 \%$ to $2.5 \%$ ) and $\mathrm{K}_{2} \mathrm{O}$ (1 to 3\%), respectively (Kang et al., 2002). Hwangto is traditionally used for disease control in livestock (Ryu, 1997). Scientific studies with animals have shown Hwangto to have improved meat quality, but not red meat quantity and feed efficiency in steers (Kang et al., 2002).

The objective of the following experiment was to compare L-carnitine, selenium-enriched yeast, Jujube fruit and Hwangto (Red clay) in finishing pig diets in order to determine whether performance or carcass quality are altered by supplementation. The effect of supplementation of L-carnitine and selenium on their deposition in muscle was also determined.

\section{MATERIALS AND METHODS}

\section{Growth trial}

Fifty castrated, male crossbred (Landrace×Yorkshire) pigs, weighing an average of $60.6 \pm 3.1 \mathrm{~kg}$, were allotted to one of five dietary treatments from outcome groups based on initial weight. The control diet was based on corn, wheat, soybean meal and wheat bran while four experimental diets were formulated by supplementing the control diet with either L-carnitine (50 ppm carnitine; Lonza, Basel,
Switzerland), selenium-enriched yeast (0.30 ppm selenium; Easybio, Seoul, Korea), 0.1\% Jujuba fruit (Medical Herb Market, Seoul, Korea) or $0.1 \%$ Hwangto (Red clay; Greenbio, Incheon, Korea) added at the expense of wheat bran (Table 1).

All diets were formulated to supply 13.8 MJ DE/kg and were supplemented with sufficient vitamins and minerals to meet or exceed the levels recommended by the National Research Council (1998). Celite 545 (1\%; Fluka, Switzerland) was added to all diets as a digestibility marker. The diets were fed in meal form.

The pigs were housed in groups of two in concrete floored pens measuring $1.2 \times 2.0 \mathrm{~m}$. Each pen contained a single feeder and a nipple waterer to provide ad libitum access to feed and water. There were five replicate pens per treatment. The temperature in the environmentally regulated finishing barn was maintained at $22 \pm 2^{\circ} \mathrm{C}$. Pigs weights and feed disappearance were recorded every $10 \mathrm{~d}$ to determine weight gain, feed intake and feed conversion.

\section{Digestibility trial}

On days 11 and 12, fecal samples were collected from each pen with the accumulation of the two-day fecal collection subsequently being pooled. The fecal samples were oven dried for $72 \mathrm{~h}$ at $55^{\circ} \mathrm{C}$, allowed to equilibrate for $24 \mathrm{~h}$ at room temperature and then ground through a 1.0 mm screen with a Cyclotec (Model 1093, FOSS, Denmark). Digestibility coefficients for dry matter, organic matter, 
Table 2. Effect of L-carnitine, selenium-enriched yeast, Jujube fruit and Hwangto supplementation on pig performance during the finishing period (60.6-110 kg) ${ }^{\mathrm{a}}$

\begin{tabular}{lccccccc}
\hline & Control & Carnitine & Selenium & Jujube fruit & Hwangto & SEM & p value \\
\hline Weight gain (kg/day) & 1.01 & 1.06 & 1.02 & 1.09 & 1.10 & 0.05 & 0.57 \\
Feed intake (kg/day) & 3.17 & 3.09 & 2.95 & 3.21 & 3.13 & 0.11 & 0.52 \\
Feed conversion & 3.15 & 2.94 & 2.90 & 2.95 & 2.84 & 0.10 & 0.32 \\
\hline
\end{tabular}

${ }^{\mathrm{a}}$ Five replicate pens of two pigs per pen for the performance data.

crude protein, crude fibre and gross energy were calculated using the equations for the indicator method described by Schneider and Flatt (1975).

\section{Carcass measurements}

The pigs were slaughtered at a commercial abattoir at an average weight of approximately $110 \mathrm{~kg}$. The pigs were weighed, stunned, hoisted by one hind leg, and exsanguinated. Carcass weight was recorded and dressing percentage calculated. Hot carcass measurements were recorded after conventional slaughtering. The carcass was chilled overnight and backfat measurements were made at the $1^{\text {st }}, 10^{\text {th }}$ and last rib midline using a ruler. The carcass was then cut into standard wholesale cuts of tenderloin, bacon, Boston butt, Picnic shoulder, skirt, ham, loin, ribs, bone and fat using procedures described by the Korean Rural Development Administration (1997). Weights of each cut were determined. The shoulder was separated from the loin and bacon by a straight cut between the $5^{\text {th }}$ and $6^{\text {th }}$ rib. It was then separated into the Boston butt and Picnic shoulder retail cuts by a straight cut along the inner side of scapula. Each cut contained its corresponding skin and subcutaneous fat. The ham was removed from the loin by a straight cut between the sacral and lumbar vertebrate.

\section{Chemical analysis}

Samples of the rations were analyzed in triplicate according to the methods of the Association of Official Analytical Chemists (1990). Analyses were conducted for moisture (AOAC method 930.15), crude protein (AOAC method 984.13), acid detergent fibre (AOAC method 962.09), ash (AOAC method 942.05) and ether extract (AOAC method 920.39). Calcium was determined by an atomic absorption Spectrophotometer (Shimazu, AA625, Japan), and phosphorus was analyzed using a UV-vis. Spectrophotometer (Hitachi, U-1100, Japan). Gross energy value of diets and feces were measured using an Adiabatic Oxygen Bomb Calorimeter (Model 1241, Parr Instrument Co., Molin, IL). Celite (HCL-Insoluble Ash) analysis was conducted according to the description provided by Prabucki et al. (1975).

A tissue sample was taken from each carcass from the longissimus muscle, between the $11^{\text {th }}$ and $12^{\text {th }}$ rib, for the determination of tissue carnitine concentrations using the method described by Bhuiyan et al. (1992). Muscle tissues were homogenized in $1 \mathrm{~mL}$ of ice-cold $1 \mathrm{~mol} / \mathrm{L} \mathrm{HClO}_{4}$ using a PowerGen Homogenizer (Model 700; Fisher Scientific; $6 \times 10 \mathrm{~s}$ at $30,000 \mathrm{rpm}$ ). Three carnitine fractions (free, short-chain and long-chain esters) were assayed the enzymatic radioisotope using the method of McGarry and Foster (1976). The tissues were analyzed for their selenium content with the fluorometric method of the AOAC (1995).

\section{Loin color determination}

To determine the color of the loin sections, loin muscles were cut into eight sections according to vertebra location. Samples were taken over the $6^{\text {th }}, 8^{\text {th }}, 10^{\text {th }}, 12^{\text {th }}$ and $14^{\text {th }}$ thoracic vertebra as well as the $2^{\text {nd }}, 4^{\text {th }}$ and $6^{\text {th }}$ lumbar vertebra. These fresh cuts were placed on stainless steel trays for approximately $2 \mathrm{~h}$, and then the Hunter $\mathrm{L}^{*}, \mathrm{a}^{*}$, and $b^{*}$ values were measured using a Chromometer $50-\mathrm{mm}$ orifice (Minolta Model CR-300, Ramsey, NJ). The average of three readings was utilized. The $\mathrm{L}^{*}$ reading is a measure of the whiteness of a sample, the $a^{*}$ reading is a measure of the redness of the sample (the more positive the number, the redder the sample), while the $b^{*}$ reading is a measure of yellowness (the more positive the number, the more yellow the sample).

\section{Statistical analysis}

The data were analyzed as a randomized block design using the Analysis of Variance procedures described by Snedecor and Cochran (1980). Pigs were blocked on the basis of initial weight and the pen was considered the experimental unit for analyses of performance and nutrient digestibility. For tissue carnitine and selenium concentration, carcass traits and cut and Hunter measurements, the individual animal data were analyzed. The model included the effects of replication (i.e., block), treatment, and replication $\times$ treatment (error). The significance of differences between means was performed by the Least Significant Difference (LSD) method when preceded by a significant F-test. Statistical analyses of Hunter color values measurement was performed with the two-way analysis of variance procedures of Snedecor and Cochran (1980) with the General AOV procedure of STASISTIX (1996). The factors in the model consisted of treatment and location as well as their interaction.

\section{RESULTS}

The effects of L-carnitine, selenium-enriched yeast, 
Table 3. Effect of L-carnitine, selenium-enriched yeast, Jujube fruit and Hwangto supplementation on nutrient digestibility (\%) for finishing pigs

\begin{tabular}{lccccccc}
\hline & Control & Carnitine & Selenium & Jujube fruit & Hwangto & SEM & p value \\
\hline Dry matter & 80.6 & 81.2 & 80.0 & 82.8 & 81.4 & 3.73 & 0.60 \\
Organic matter & 85.4 & 85.4 & 84.4 & 86.2 & 85.4 & 0.91 & 0.74 \\
Crude protein & 76.8 & 79.6 & 76.8 & 80.0 & 78.4 & 2.19 & 0.76 \\
Crude fibre & 44.8 & 42.4 & 43.6 & 43.0 & 45.0 & 1.52 & 0.70 \\
Gross energy & 81.4 & 81.6 & 81.0 & 83.4 & 82.0 & 1.33 & 0.75 \\
\hline
\end{tabular}

${ }^{\mathrm{a}}$ Five replicate pens (two castrates per pen) per treatment mean.

Table 4. Effect of L-carnitine, selenium-enriched yeast, Jujube fruit and Hwangto supplementation on tissue carnitine and selenium concentrations at $110 \mathrm{~kg}$ body weight*

\begin{tabular}{lccccccc}
\hline & Control & Carnitine & Selenium & Jujube fruit & Hwangto & SEM & p value \\
\hline Carnitine $(\mathrm{nM} / \mathrm{g} D M)$ & $806.1^{\mathrm{a}}$ & $1,285.6^{\mathrm{b}}$ & $921.3^{\mathrm{a}}$ & $897.4^{\mathrm{a}}$ & $848.8^{\mathrm{a}}$ & 44.5 & 0.0001 \\
Selenium $(\mu \mathrm{g} / \mathrm{kg} \mathrm{DM})$ & $631.3^{\mathrm{a}}$ & $644.0^{\mathrm{a}}$ & $1,250.0^{\mathrm{b}}$ & $704.3^{\mathrm{a}}$ & $616.3^{\mathrm{a}}$ & 63.3 & 0.0001 \\
\hline
\end{tabular}

$\overline{\mathrm{a}, \mathrm{b}}$ Means within a row with different superscripts differ at the $\mathrm{p}$-values indicated.

* Based on five pigs per treatment.

Table 5. Effect of L-carnitine, selenium-enriched yeast, Jujube fruit and Hwangto supplementation on swine carcass traits ${ }^{\mathrm{a}}$

\begin{tabular}{lccccccc}
\hline & Control & Carnitine & Selenium & Jujube fruit & Hwangto & SEM & p value \\
\hline Slaughter weight (kg) & 107.0 & 109.5 & 107.1 & 110.6 & 111.3 & 3.15 & 0.81 \\
Carcass weight (kg) & 79.8 & 81.5 & 80.0 & 82.5 & 83.3 & 2.36 & 0.79 \\
Dressing percentage & 74.6 & 74.5 & 74.7 & 74.6 & 74.9 & 0.14 & 0.33 \\
Lean yield (\%) & 66.3 & 66.8 & 66.7 & 66.6 & 66.5 & 0.71 & 0.99 \\
Midline back fat & & & & & & & \\
$\quad$ First rib (mm) & 44.1 & 38.7 & 43.8 & 41.5 & 41.4 & 2.22 & 0.45 \\
$\quad 10^{\text {th }}$ rib (mm) & 30.5 & 27.3 & 28.8 & 27.5 & 28.9 & 2.12 & 0.82 \\
$\quad$ Last rib (mm) & 26.7 & 21.7 & 22.6 & 22.5 & 23.1 & 2.04 & 0.47 \\
\hline
\end{tabular}

${ }^{\mathrm{a}}$ Based on five pigs per treatment.

Table 6. Effect of L-carnitine, selenium-enriched yeast, Jujube fruit and Hwangto supplementation on the percentage of the carcass comprised of various retail cuts*

\begin{tabular}{lccccccc}
\hline & Control & Carnitine & Selenium & Jujube fruit & Hwangto & SEM & p value \\
\hline Tenderloin & 1.48 & 1.38 & 1.47 & 1.46 & 1.52 & 0.05 & 0.37 \\
Bacon & 12.67 & 12.22 & 12.57 & 11.68 & 12.10 & 0.37 & 0.36 \\
Boston butt & $6.17^{\mathrm{ab}}$ & $5.93^{\mathrm{bc}}$ & $5.60^{\mathrm{c}}$ & $6.42^{\mathrm{a}}$ & $6.18^{\mathrm{ab}}$ & 0.14 & 0.01 \\
Fat+bone & 33.43 & 33.03 & 32.70 & 33.20 & 32.02 & 0.63 & 0.56 \\
Picnic shoulder & 12.35 & 12.82 & 13.01 & 13.40 & 12.72 & 0.32 & 0.25 \\
Skirt & 0.48 & 0.44 & 0.43 & 0.44 & 0.47 & 0.04 & 0.80 \\
Fresh ham & 19.53 & 20.50 & 20.52 & 20.31 & 20.46 & 0.37 & 0.31 \\
Loin & $8.57^{\mathrm{ab}}$ & $8.48^{\mathrm{ab}}$ & $7.91^{\mathrm{b}}$ & $7.93^{\mathrm{b}}$ & $9.06^{\mathrm{a}}$ & 0.26 & 0.04 \\
Ribs & 5.12 & 5.00 & 5.21 & 4.89 & 5.08 & 0.18 & 0.79 \\
\hline
\end{tabular}

${ }_{a, b, c}$ Means within a row with different superscripts differ at the p-values indicated.

* Based on five pigs per treatment.

Jujube fruit and Hwangto on pig performance are shown in Table 2. Dietary supplementation with L-carnitine, selenium-enriched yeast, Jujube fruit and Hwangto did not influence weight gain $(p=0.57)$, feed intake $(p=0.52)$ or feed conversion $(\mathrm{p}=0.32)$. Digestibility of dry matter $(\mathrm{p}=$ $0.60)$, organic matter $(p=0.74)$, crude protein $(p=0.76)$, crude fibre $(0.70)$ and energy $(p=0.75)$ were also unaffected by any of the feed additives (Table 3 ).

Tissue samples taken from the longissimus muscle showed that the level of carnitine $(p=0.0001)$ or selenium $(\mathrm{p}=0.0001)$ present in tissue was significantly higher as dietary carnitine or selenium-enriched yeast was added to the diet (Table 4). For all other treatments, tissue carnitine and selenium levels did not differ from those of the control treatment.

The effects of feeding diets with L-Carnitine, Seleniumenriched yeast, Jujube fruit and Hwangto supplementation on swine carcass traits are shown in Table 5. Dietary treatment did not affect dressing percentage ( $p=0.33$ ), carcass lean yield $(p=0.99)$ or middle line backfat depth at the first $(p=0.45), 10^{\text {th }}(p=0.82)$ or last rib $(p=0.47)$.

The effects of feeding diets with L-carnitine, seleniumenriched yeast, Jujube fruit and Hwangto supplementation during the finishing period on the percentage various retail cuts comprise of the total carcass are shown in Table 6 . Dietary treatment did not affect percentages of tenderloin ( $p$ 
Table 7. Effect of L-carnitine, selenium-enriched yeast, Jujube fruit and Hwangto supplementation and loin position on Hunter color values (L*, whiteness; $a^{*}$, redness; $b^{*}$, yellowness) of loin ${ }^{\mathrm{a}}$

\begin{tabular}{lcccccccc}
\hline Item & \multirow{2}{*}{ Control } & \multirow{2}{*}{ Carnitine } & \multirow{2}{*}{ Selenium } & \multirow{2}{*}{ Jujube fruit } & \multirow{2}{*}{ Hwangto } & SEM & \multicolumn{2}{c}{$P$-value } \\
\cline { 7 - 9 } & & & & & & & Treatment & Position \\
\hline $\mathrm{L}^{\mathrm{b}}$ & $59.0^{\mathrm{a}}$ & $56.6^{\mathrm{b}}$ & $58.7^{\mathrm{a}}$ & $58.7^{\mathrm{a}}$ & $58.3^{\mathrm{a}}$ & 0.45 & 0.004 & 0.001 \\
$\mathrm{a}^{*}$ & $8.1^{\mathrm{bc}}$ & $8.6^{\mathrm{a}}$ & $7.7^{\mathrm{c}}$ & $8.4^{\mathrm{ab}}$ & $8.1^{\mathrm{abc}}$ & 0.15 & 0.069 & 0.006 \\
$\mathrm{~b}^{*}$ & 3.0 & 2.5 & 2.9 & 3.3 & 2.6 & 0.24 & 0.193 & 0.001 \\
\hline $\mathrm{a}$
\end{tabular}

${ }^{\mathrm{a}}$ Based on six pigs per treatment.

$=0.37)$, bacon $(p=0.36)$, fat and bone $(p=0.56)$, skirt $(p=$ $0.80)$, fresh ham $(p=0.31)$, or ribs $(p=0.79)$. Compared with pigs fed either the control, Jujube fruit or Hwangto diets, pigs fed the diet containing added selenium had a lower ( $p=0.01$ ) percentage of Boston butt in the carcass. However, pigs fed diet containing added Jujube fruit had a higher ( $p=0.01$ ) percentage of Boston butt in the carcass than pigs fed either the L-carnitine or selenium supplemented diets. Compared with pigs fed the selenium or Jujube fruit diets, pigs fed the diet containing Hwangto had higher $(p=0.04)$ percentages of loin.

The effects of feeding diets with L-carnitine, seleniumenriched yeast, Jujube fruit and Hwangto supplementation during the finishing period on Hunter color values are shown in Table 7. Loin muscle from pigs fed carnitine had significantly lower Hunter colour values of L (whiteness, $p$ $=0.004)$ and higher values for $\mathrm{a}^{*}$ (redness; $\left.\mathrm{p}=0.069\right)$. The Hunter colour value $L^{*}(P=0.001)$, $a^{*}(p=0.006)$ and $b^{*}$ $(p=0.001)$ decreased as the sampling position of the muscle moved ventrally from the $5^{\text {th }}$ to $14^{\text {th }}$ thoracic vertebra and then increased as the sampling position moved ventrally from the $1^{\text {st }}$ to $6^{\text {th }}$ lumbar vertebra.

\section{DISCUSSION}

Dietary supplementation of L-carnitine, seleniumenriched yeast, Jujube fruit and Hwangto during the finishing period had no effect on pig performance. Similar to our results, Owen et al. (2001b) reported that the addition of L-carnitine did not improve the performance of finishing pigs. These results are also consistent with those of Thomke et al. (1965), Mahan and Parrett (1996) and Mahan et al. (1999), who demonstrated no growth or feed responses when an organic form of selenium was added at various levels to growing-finishing cereal grain-based diets fed to pigs. Similarly, Thacker (2003), failed to demonstrate any performance improvements using Biotite, an aluminiosilicate clay similar in composition to that used in the present experiment.

Supplementation of L-carnitine, selenium-enriched yeast, Jujube fruit and Hwangto in the diet during the finishing period was generally unsuccessful in increasing nutrient digestibility. There is little research with which to compare our findings although Thacker (2003) similarly failed to improve nutrient digestibility with an aluminosilicate clay (Biotite). However, Chen et al. (2005) found that $\mathrm{N}$ digestibility was improved by addition of Biotite V.

Tissue samples taken from the loin showed that the level of carnitine and selenium present in muscle was increased when L-carnitine and selenium-enriched yeast were included in the diet. This result supports that of Owen et al. (2001a), concluding that carnitine is synthesized in the liver and stored to some degree in the heart, but primarily in the muscle. Mahan et al. (1999) reported that dietary selenium affected the selenium concentration in the loin tissues at the end of the finishing (105 kg BW) periods. Mahan and Parrett (1996) and Mahan et al. (2005) reported that more selenium was retained in muscle tissue when a seleniumenriched yeast source was fed. Consequently, as pigs attain market weight (105-110 kg) and are fed either L-carnitine and/or organic selenium, they will have higher carnitine and/or selenium contents in tissue.

There was no significant effect on midline backfat thickness from the addition of the L-carnitine, seleniumenriched yeast, Jujube fruit and Hwangto. In contrast, Owen et al. (2001a) reported that increasing dietary L-carnitine reduced average backfat thickness; with 49 to 64 ppm Lcarnitine providing the optimum response as determined from break point analysis. Newton and Haydon (1989) also showed a decrease in backfat thickness from finishing pigs fed supplemental L-carnitine.

The failure of selenium to modify backfat levels is consistent with the results of Mahan et al. (1999). Their results and ours indicated that the major carcass characteristics were not significantly affected by dietary selenium. The lack of effect of Hwangto on carcass characteristics supports the work of Thacker (2003) who noted no changes in carcass characteristics as a result of dietary inclusion of an aluminosilicate clay (Biotite).

Feeding diets supplemented with L-carnitine, seleniumenriched yeast, Jujube fruit and Hwangto during the finishing period had no effect on the percentage that various retail cuts comprise of the carcass. This is in agreement with other researchers who reported the dietary regimens to have no significant effect on carcass cutability (Unruh et al., 1996).

Supplementation of L-carnitine during the finishing period lowered the Hunter color value L*. These responses seemed to be consistent with fat content. Owen et al. (1993) 
reported that feeding L-carnitine during the growingfinishing phase resulted in an $11 \%$ reduction in daily lipid accretion rate. Owen et al. (2001b) reported that increasing dietary L-carnitine resulted in a darker color for longissimus muscle.

Interestingly, there was a difference in Hunter color values of loin between positions. These responses seemed to be consistent with the different intramusclar fat content as the sampling position moved from thoracic to lumbar vertebra of loins. Heylen (1999) reported that the intramuscular fat content of the cranial position in longissimus is significantly higher than medial and caudal positions.

In conclusion, it would appear that supplementation of L-carnitine, selenium-enriched yeast, Jujube fruit and Hwangto in the diet during the finishing period had no significant effects on pig performance or carcass traits. However, the level of carnitine and selenium present in muscle was increased as L-carnitine and organic selenium was supplemented in the diet. As a result, it is possible to produce pork containing higher levels of carnitine and selenium, which could provide potential health benefits for consumers of pork, without negative effects on pig performance.

\section{REFERENCES}

American Dietetic Association. 2004. Functional Foods: Position of the American Dietetic Association. J. Am. Diet Assoc. 104:814-826.

Association of Official Analytical Chemists. 1990. Official Methods of Analysis, 15th edn, AOAC, Washington, DC.

Association of Official Analytical Chemists. 1995. Official Methods of Analysis, 16th edn, AOAC, Arlington, VA.

Belury, M. A. 2002. Inhibition of carcinogenesis by conjugated linoleic acid: Potential mechanisms of action. Am. J. Clin. Nutr. 132:2995-2998.

Bhuiyan, A. K. M. J., S. Jackson, D. M. Turnbull, A. AynsleyGreen, J. V. Leonard and K. Bartlett. 1992. The measurement of carnitine and acyl-carnitines: Application to the investigation of patients with suspected inherited disorders of mitochondrial fatty acid oxidation. Clin. Chim. Acta. 207:185204.

Chen, Y. J., O. S. Kwon, B. J. Min, K. S. Son, J. H. Cho, J. W. Hong and I. H. Kim. 2005. The effects of dietary Biotite V supplementation as an alternative substance to antibiotics in growing pigs. . Asian-Aust. J. Anim. Sci. 18:1642-1645.

Chevallier, A. 1998. Die BLV Enzyklopaedie der Heil Pflanze. BLV Verlagsgesselschaft, Muenchen. p. 281.

Farrell, D. J. 1998. Enrichment of hen eggs with n-3 long-chain fatty acids and evaluation of enriched eggs in humans. Am. J. Clin. Nutr. 68:538-544.

Fritz, I. B. and K. T. N. Yue. 1963. Long-chain carnitine acyltransferase and the role of acylcarnitine derivatives in the catalytic increase of fatty acid oxidation induced by carnitine. J. Lipid. Res. 4:279-288.
Han, Y. K., D. K. Kim and J. Y. Lee. 2001. Effects of Zizyphus Vulgaris supplementation on growth and blood cortisol and $\beta$ endorphin in weanling pigs. Kyunghee Med. 17:183-186.

Heylen, K. 1999. Variation von anatomosch-physiologischen Merkmalen sowie Merkmalen der Fleischqualitaet im M.longissimus thoracis et lumborum des Schweines unter besonderer Beruecksichtigung des intramusklaeren Fettgehaltes. Dissertation. Institut fuer Tierzucht und Tierhaltung mit Tierklinik, Martin-Luther-Universitaet HalleWittenberg, Halle.

Kang, S. W., J. S. Kim, W. M. Cho, H. Y. Chung, K. S. Ki and S. B. Choi. 2002. Effect of red clay (Hwangto) on growth performance and carcass characteristics in growing-fattening Hanwoo steers. J. Anim. Sci. Technol. (Kor). 44:315-326.

Korean Rural Development Administration. 1997. Methods for the pork carcass dissection. CD-Rom version.

Ku, P. K., W. T. Ely, A. W. Groce and D. E. Ullrey. 1972. Natural dietary selenium, $\alpha$-tocopherol and effect on tissue selenium. J. Anim. Sci. 34:208-211.

Lewis, N. M., S. Seburg and N. L. Flanagan. 2000. Enriched eggs as a source of n-3 polyunsaturated fatty acids for humans. Poult. Sci. 79:971-974.

Mahan, D. C., T. R. Cline and B. Richert. 1999. Effects of dietary levels of selenium-enriched yeast and sodium selenite as selenium sources fed to growing-finishing pigs on performance, tissue selenium, serum glutathione peroxidase activity, carcass characteristics, and loin quality. J. Anim. Sci. 77:2172-2179.

Mahan, D. C. and N. A. Parrett. 1996. Evaluating the efficacy of selenium-enriched yeast and sodium selenite on tissue selenium retention and serum glutathione peroxidase activity in grower and finisher swine. J. Anim. Sci. 74:2967-2974.

Mahan, D. C., J. H. Brendemuhl, S. D. Carter, L. I. Chiba, T. D. Crenshaw, G. L. Cromwell, C. R. Dove, A. F. Harper, G. M. Hill, G. R. Hollis, S. W. Kim, M. D. Lindemann, C. V. Maxwell, P. S. Miller, J. L. Nelssen, B. T. Richert, L. L. Southern, T. S. Stahly, H. H. Stein, E. van Heugten and J. T. Yen. 2005. Comparison of dietary selenium fed to growerfinisher pigs from various regions of the United States on resulting tissue Se and loin mineral concentrations. J. Anim. Sci. 83:852-857.

McGarry, J. D. and D. W. Foster. 1976. An improved and simplified radioisotopic assay for the determination of free and esterified carnitine. J. Lipid Res. 17:277-281.

National Research Council. 1998. Nutrient Requirements of Swine. $10^{\text {th }}$ ed. NAS-NRC, Washington, DC.

Newton, G. L. and K. D. Haydon. 1989. Carnitine supplementation for finishing pigs. J. Anim. Sci. 67 (Suppl. 1):267(Abstr.).

Ou, M. 1989. Chinese-English Manual of Common-Used Herbs in Traditional Chinese Medicine. Joint Publishing Co., Hong Kong.

Owen, K. Q., T. L. Weeden, J. L. Nelssen, S. A. Blum and R. D. Goodband. 1993. The effect of L-carnitine additions on performance and carcass characteristics of growing-finishing swine. J. Anim. Sci. 71(Suppl. 1):62 (Abstr.).

Owen, K. Q., J. L. Nelssen, R. D. Goodband, M. D. Tokach and K. G. Friesen. 2001a. Effect of dietary L-carnitine on growth performance and body composition in nursery and growingfinishing pigs. J. Anim. Sci. 79:1509-1515. 
Owen, K. Q., H. Ji, C. V. Maxwell, J. L. Nelssen, R. D. Goodband, M. D. Tokach, G. C. Tremblay and S. I. Koo. 2001b. Dietary L-carnitine suppresses mitochondrial branched-chain keto acid dehydrogenase activity and enhances protein accretion and carcass characteristics of swine. J. Anim. Sci. 79:3104-3112.

Park, K. M., Y. K. Han and K. W. Park. 2000. Effects of Jujube fruit-mix supplementation on the growth performance and serum growth hormone in weaned pigs. Asian-Aust. J. Anim. Sci. 13:791-794.

Prabucki, A. L., L. Rennerova, H. Vogtmann, C. Wenk and A. Schuerch. 1975. Die Verwendung von 4-N HCL-unloeslicher Asche als Indikator zur Bestimmung der Verdaulichkeit. Institut fuer Tierernaehrung, ETH Zuerich. Misc. Pap. Landbouwhogesch. Weningen. 11:113-114.

Ryu, D. O. 1997. The miracle red clay. ISBN:8972924059. Haengrim Publishing Company, Seoul.

Schneider, B. H. and W. P. Flatt. 1975. The Evaluation of Feeds Through Digestibility Experiments. University of Georgia Press, Athens, Georgia p. 423.
Snedecor, G. W. and W. G. Cochran. 1980. Statistical Methods. $7^{\text {th }}$ ed. The Iowa State University Press. Ames, Iowa.

Thacker, P. A. 2003. Performance of growing-finishing pigs fed diets containing graded levels of Biotite, an aluminosilicate clay. Asian-Aust. J. Anim. Sci. 16:1666-1672.

Thomke, K. E., O. Dahl and K. A. Persson. 1965. Tocopherol and selenium in pig rations, including an assessment of meat quality parameters. Acta. Agric. Scand. 15:262-274.

Unruh, J. A., K. G. Friesen, S. R. Stuewe, B. L. Dunn, J. L. Nelssen, R. D. Goodband and M. D. Tokach. 1996. The influence of genotype, sex, and dietary lysine on pork subprimal cut yields and carcass quality of pigs fed to either 104 or 127 kilograms. J. Anim. Sci. 74:274-1283.

Wildman, R. E. 2001. Nutraceuticals: A brief review of historical and teleological aspects. In: Handbook of Nutraceuticals and Functional Foods. (Ed. R. E. Wildman). CRC Press, Boca Raton, Florida, pp. 1-12.

Yang, S. Z. 1998. The Divine Farmer's Materia Medica. Blue Poppy Press. Boulder, Co. 